\title{
Diffusion Tests for Chloride in Concrete Using Wind Tunnel Test
}

\author{
Devi Nuralinah ${ }^{1, *}$, and Takumi Shimomura ${ }^{2}$ \\ ${ }^{1}$ Civil Engineering Department, Brawijaya University, 65145 Jl. MT. Haryono 167 Malang, Indonesia \\ ${ }^{2}$ Environmental and Civil Engineering Department, Nagaoka University of Technology, 940-2188 \\ Kamitomioka Machi 1603-1, Nagaoka-Niigata, Japan
}

\begin{abstract}
Diffusion coefficient of chloride in concrete is a predominant factor in chloride penetration into concrete. Two types of diffusion coefficient models are examined here: mean diffusion coefficient $D$, timedependent diffusion coefficient $D(t)$. These diffusion coefficients are experimentally derived from the chloride profiles in concrete obtained by the wind tunnel test. It is clearly shown that diffusion coefficients are dependent of water cement ratio but independent of intensity of airborne salt. Time-dependent diffusion coefficients derived based on constant and time-dependent surface chloride are not different. Diffusion coefficient also decreases with increasing of time as explained by other researcher.
\end{abstract}

\section{Introduction}

Chloride ingress in concrete is usually expressed by Fick's diffusion equation to practically estimate service-life of concrete structures. In the Standard Specification for Concrete Structures by Japan Society of Civil Engineers, the state in which chloride content at the reinforcing bar portion in concrete reaches the designated threshold value is defined as one of the limit states of structural durability [1]. In the JSCE method, surface chloride content is used as boundary condition for diffusion of chloride in concrete. It is empirically determined based on distance from the shore line. Diffusion coefficient is estimated from concrete properties by means of concrete water-cement ratio and type of cement.

Surface chloride and diffusion coefficient have been investigated in many previous studies. The resistance of concrete to chloride penetration was investigated by the rapid chloride permeability test [2]. The chloride penetration in unsaturated concrete skin was different from that in concrete bulk [3]. Chloride ion diffusion coefficient decreases in long-term chloride exposure [4].

Diffusion coefficient of chloride in concrete is a predominant factor in chloride penetration into concrete. Two types of diffusion coefficient models experimentally derived from the chloride profiles in concrete obtained by the wind tunnel test were examined here: mean diffusion coefficient $D$, and time-dependent diffusion coefficient $D(t)[5,6]$.

In this paper, relationship between intensity of airborne salt and surface chloride content was investigated based on the test results obtained by the developed testing equipment. On

* Corresponding author: devi@ub.ac.id 
the other hand, diffusion coefficients derived from the obtained chloride profile in all specimens are also discussed.

It is well-known that experimentally obtained diffusion coefficient of chlorides in concrete decreases with increasing of exposure time. One of the practical ways to express this tendency in computational model is to regard diffusion coefficient as a function of time, as adopted in many previous studies. If the reason of decreasing of diffusion coefficient is change of pore structure of concrete, time-dependent diffusion coefficient is reasonable.

However, if the true reason for this is that transport of chloride in concrete is not simple diffusion mechanism, then time-dependent diffusion coefficient is not universal way to express the experimental results.

\section{Research method}

In previous paper, chloride ingress into concrete subjected to airborne salt was developed by wind tunnel test [5-7]. The inside views of that apparatus shown in Fig. 1 has size $1 \mathrm{mx} 1 \mathrm{~m}$. The wind path has a length of $12 \mathrm{~m}$ in one round. Propeller that generates air flow with diameter of $90 \mathrm{~cm}$ was set up in the first floor as shown in Fig. 1(a), as well as driven by an electric motor installed outside of the device. Particles of salt water were produced by putting fine air bubbles into 3\% salt water in a bath (Fig. 1(b)). Six concrete specimens whose size is $100 \times 100 \times 150 \mathrm{~m}$, were prepared with water-cement ratio of $40 \%$ and $60 \%$, and cured in water for 28-days. After curing, five surfaces of each specimen were coated with tar epoxy except the exposed surface to ensure one-dimensional chloride ingress into concrete from the exposed surface. Both concrete specimens and gauze specimens were set up and exposed to the airborne salt in the first and the second floor in the wind tunnel as shown respectively in Fig. 1(c) and 1(d). The wind velocity in the tunnel was $1.5 \mathrm{~m} / \mathrm{s}$. The measured airborne salt per unit area per unit time, which was expressed in terms of amount of Natrium Chloride was 5 to $68.2 \mathrm{mdd}\left(\mathrm{mg} / \mathrm{dm}^{2} /\right.$ day) depending on the testing position in the wind tunnel.

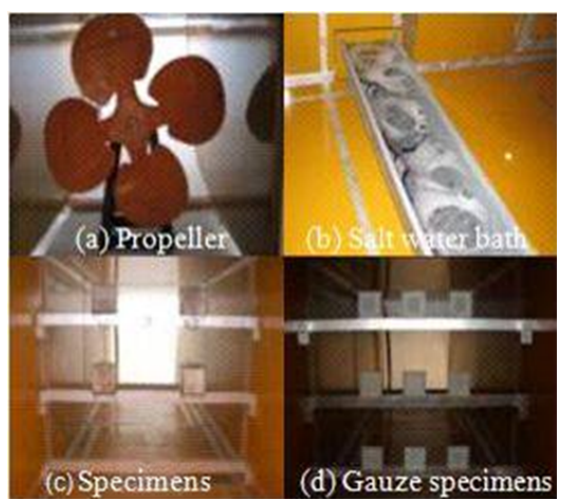

Fig. 1. The inside views of wind tunnel.

Specimens were taken out from the wind tunnel occasionally and chloride content in concrete was measured. From the beginning up to 96 days, samples of concrete powder were taken at the positions of $10 \mathrm{~mm}, 20 \mathrm{~mm}$, and $40 \mathrm{~mm}$ from the exposed surface by drilling from both side surface to the maximum depth of drilled hole. After 96 days, samples were also obtained at the point of 60 and $80 \mathrm{~mm}$ from the exposed surface to measure chloride content in deeper portion. Value of chloride content in concrete is 
expressed in terms of amount of chloride ion per unit volume. After chloride content measurement, specimens were exposed again in the tunnel.

\section{Determination of experimental diffusion coefficient}

The result of experimental time-dependent chloride profiles in specimen $\mathrm{H}-40$ obtained by wind tunnel test during 240 days is shown as example in Fig. 2.

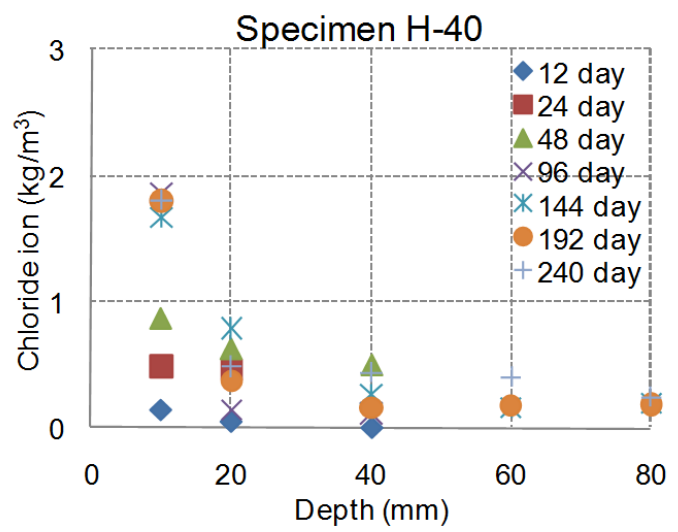

Fig. 2. Time-dependent chloride profiles in concrete specimen H-40.

Transport process of chloride in concrete is evaluated by Fick's diffusion equation coupled-with fixed boundary condition as a standard and most popular method [8-10].

$$
\begin{aligned}
& \frac{\partial C}{\partial t}=D \frac{\partial^{2} C}{\partial x^{2}} \\
& C(0, t)=C_{0}
\end{aligned}
$$

Integral solution of the governing differential equation of Equation. (1) under the boundary condition Equation. (2) in semi-infinity body is expressed as:

$$
C(x, t)=C_{0}\left\{1-\operatorname{erf}\left(\frac{x}{2 \sqrt{D t}}\right)\right\}
$$

where, $\operatorname{erf}(\mathrm{s})$ is an error function defined as:

$$
\operatorname{erf}(s)=\frac{2}{\sqrt{\pi}} \int_{0}^{s} e^{-\eta^{2}} d \eta
$$

Equation. (3) is often used as practical design equation to estimate service-life of structures since it is convenient to calculate chloride content at the reinforcing bar position in concrete as a function of service time.

Time-dependent and constant diffusion coefficients are derived from the wind tunnel test as examined by other research's group according to following procedure.

i) Transforming Equation. (3), mean diffusion coefficient at the position $x_{i}$ and at the time $t_{j}$ is expressed as: 


$$
D_{i, j}=\frac{1}{t_{j}\left\{\frac{2}{x_{i}} \operatorname{erf}^{-1}\left(1-\frac{C\left(x_{i}, t_{j}\right)}{C_{0}}\right)\right\}^{2}}
$$

where,

$C\left(x_{i}, t_{j}\right)$ : experimentally obtained chloride content in concrete at the position $x_{i}$ and at the time $t_{j}$;

$C_{0}$ : surface chloride content. Either mean or time-dependent surface chloride content is used in Equation. (5). Surface chloride content at time $\mathrm{t}$ is estimated by extrapolation method

ii) The obtained surface chloride content $C_{0}\left(t_{j}\right)$ at the sampling time $t_{j}$ is plotted as a function of time. Then, time-dependent surface chloride content $C_{0}(t)$ is simulated by a regression curve expressed by Equation. (6).

$$
C_{0}(t)=a\left(1-e^{-b t}\right)
$$

where;

$a, b:$ parameters for time-dependent surface chloride content determined by least square method.

iii) Then, mean surface chloride during the exposure period is mathematically calculated by averaging $C_{0}\left(t_{j}\right)$ with respect to time by Equation. (7).

$$
C_{0}=\frac{1}{T} \sum_{0}^{T} C_{0}\left(t_{j}\right) \Delta t_{j}
$$

where,

$T$ : length of time of exposure (day)

$C_{0}\left(t_{j}\right)$ : experimental time-dependent surface chloride content

iv) Series of diffusion coefficient $D_{i, j}$ obtained from the experimental chloride content at each position at the exposure time $t_{j}$ is averaged with respect to position.

$$
D_{j}=\frac{1}{X} \sum_{i} D_{i, j} \Delta x_{i}
$$

where,

$X$ : depth of specimen (mm)

$\Delta x_{i}:$ distance between measurement positions ( $\mathrm{mm}$ )

v) Thereafter, regression curve for time-dependent diffusion coefficient $D(t)$ expressed by Equation. (9) is approved to approximate $D_{j}$.

$$
D(t)=c t^{-d}
$$

where;

$c$ and $d$ : parameters for time-dependent diffusion coefficient, which are determined by least square method.

It should be noted that diffusion coefficient obtained by the above procedure is not a theoretical time-dependent diffusion coefficient, because the integral solution Equation. (3) 
is based on constant diffusion coefficient. Therefore, diffusion coefficient evaluated by Equation. (5) is considered only as an approximated value of time-dependent diffusion coefficient.

vi) Mean diffusion coefficient in Equation. (10) is mathematically calculated by averaging Equation. (8) with respect to time.

$$
D=\frac{1}{T} \sum_{0}^{T} D_{j} \Delta t_{j}
$$

where;

$T$ : exposure time of specimen

$D_{j}$ : experimental time-dependent diffusion coefficient as expressed by Eq. (8).

\section{Result and discussion}

Time-dependent diffusion coefficients of specimens $\mathrm{H}-40$ as example derived from data of 0-240 day under mean and time-dependent surface chloride is shown in Fig. 3 and summarized in Table 1. Two diffusion coefficients both decrease with increasing of time and approach to a same value in long time. Diffusion coefficient based on mean surface chloride $D_{1}(t)$ and time-dependent surface chloride $D_{2}(t)$ are close to each other except in early stage of exposure.

Diffusion coefficients based on mean and time-dependent surface chloride in the series of $60 \%$ of $\mathrm{W} / \mathrm{C}$ are relatively greater than those in the series of $40 \%$ of $\mathrm{W} / \mathrm{C}$. It seems that diffusion coefficients are independent from intensity of airborne salt. Considering these facts, diffusion coefficient can be regarded as material properties independent of environmental condition.

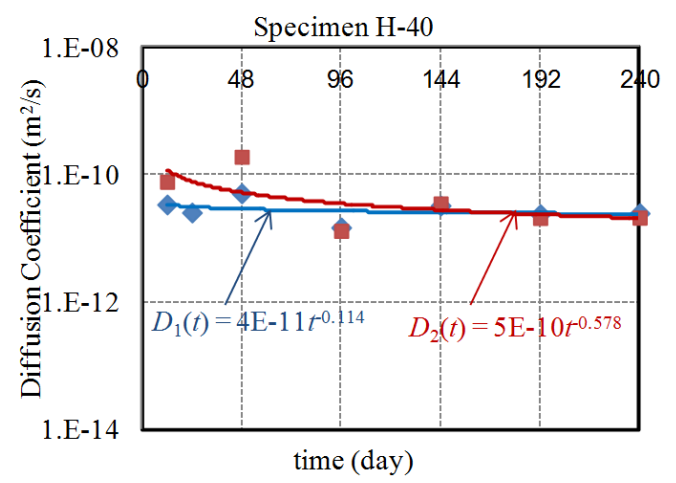

Fig. 3. Time-dependent diffusion coefficient of all specimens derived from 0-240 day data.

Same as many previous studies, experimentally obtained apparent diffusion coefficient of chlorides in concrete in the present study decreases with increasing of exposure time. There are two possible reasons for this. The first is the change of pore structure of concrete during exposure due to cement hydration. The other is that transport phenomena of chloride in concrete cannot be expressed by ideal diffusion equation in reality. If the first reason is dominant, then using time-dependent diffusion coefficient is reasonable. On the other hand, if the second reason is true, using time-dependent diffusion coefficient is not universal way to express the phenomenon because pore structure of concrete does not change. Thus, the relationship between diffusion coefficient and time is affected by environmental condition. 
In Fig. 4, time-dependent diffusion coefficients of specimens with high water-cement ratio are relatively higher than those with low water-cement ratio. Diffusion coefficients derived under time-dependent surface chloride are greater than those derived under constant surface chloride in early stage of exposure. However, they almost become same value in long time of exposure.

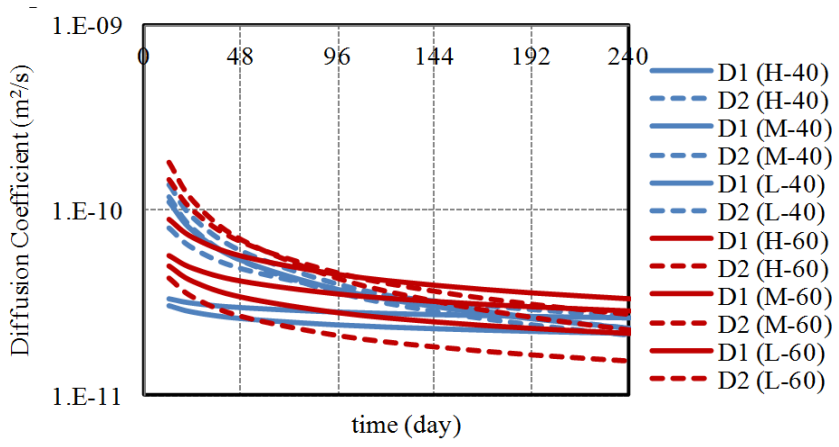

Fig. 4. Time-dependent diffusion coefficient of all specimens derived from 0-240 day data.

Furthermore, mean diffusion coefficient is derived from data of 0-240 day under either mean or time-dependent surface chloride. The results of mean diffusion coefficient are also summarized in Table 1. Relationship between $W / C$ and diffusion coefficient $D_{1}$, which is averaged $D_{1}(t)$, is shown in Fig. 5. The influence of intensity of airborne salt on diffusion coefficient is not apparent.

Table 1. Time-dependent and mean diffusion coefficient derived from 0-240 day data.

\begin{tabular}{|c|c|c|c|c|}
\hline \multirow{3}{*}{ Specimen } & \multicolumn{2}{|c|}{$\begin{array}{c}\text { Time-dependent } \\
\text { diffusion coefficient }\left(\mathbf{m}^{\mathbf{2}} / \mathbf{s}\right)\end{array}$} & \multicolumn{2}{c|}{$\begin{array}{c}\text { Mean } \\
\text { diffusion coefficient }\left(\mathbf{m}^{\mathbf{2}} / \mathbf{s}\right)\end{array}$} \\
\cline { 2 - 5 } & $\begin{array}{c}\boldsymbol{D}_{\mathbf{1}}(\boldsymbol{t}) \\
\text { based on } \boldsymbol{C}_{\mathbf{0}}\end{array}$ & $\begin{array}{c}\boldsymbol{D}_{\mathbf{2}}(\boldsymbol{t}) \\
\text { based on } \boldsymbol{C}_{\mathbf{0}}(\boldsymbol{t})\end{array}$ & $\begin{array}{c}\text { Mean } \boldsymbol{D}_{\mathbf{1}} \\
\text { based on } \boldsymbol{C}_{\mathbf{0}}\end{array}$ & $\begin{array}{c}\text { Mean } \boldsymbol{D}_{\mathbf{2}} \\
\text { based on } \boldsymbol{C}_{\mathbf{0}}(\boldsymbol{t})\end{array}$ \\
\hline $\mathrm{H}-40$ & $4 \mathrm{E}-11 \mathrm{t}^{-0.114}$ & $5 \mathrm{E}-10 \mathrm{t}^{-0.578}$ & $2.67 \mathrm{E}-11$ & $4.00 \mathrm{E}-11$ \\
\hline $\mathrm{M}-40$ & $4 \mathrm{E}-11 \mathrm{t}^{-0.079}$ & $2 \mathrm{E}-10 \mathrm{t}^{-0.368}$ & $2.87 \mathrm{E}-11$ & $3.78 \mathrm{E}-11$ \\
\hline $\mathrm{L}-40$ & $4 \mathrm{E}-10 \mathrm{t}^{-0.521}$ & $6 \mathrm{E}-10 \mathrm{t}^{-0.597}$ & $3.02 \mathrm{E}-11$ & $8.45 \mathrm{E}-11$ \\
\hline $\mathrm{H}-60$ & $1 \mathrm{E}-10 \mathrm{t}^{-0.231}$ & $6 \mathrm{E}-10 \mathrm{t}^{-0.565}$ & $3.54 \mathrm{E}-11$ & $6.30 \mathrm{E}-11$ \\
\hline $\mathrm{M}-60$ & $1 \mathrm{E}-10 \mathrm{t}^{-0.281}$ & $1 \mathrm{E}-10 \mathrm{t}^{-0.343}$ & $3.11 \mathrm{E}-11$ & $3.16 \mathrm{E}-11$ \\
\hline $\mathrm{L}-60$ & $2 \mathrm{E}-10 \mathrm{t}^{-0.328}$ & $1 \mathrm{E}-09 \mathrm{t}^{-0.691}$ & $4.29 \mathrm{E}-11$ & $7.52 \mathrm{E}-11$ \\
\hline
\end{tabular}

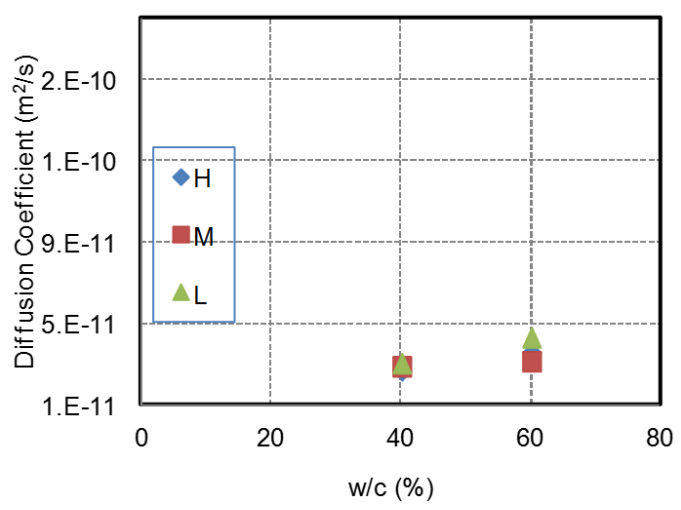

Fig. 5. Relationship between $\mathrm{W} / \mathrm{C}$ and mean diffusion coefficient $\mathrm{D}_{1}$ derived from $0-240$ day data. 


\section{Conclusion}

Two types of diffusion coefficient, which are mean diffusion coefficient $D$, time-dependent diffusion coefficient $D(t)$, were derived from the exposure test result by the wind tunnel. The results are concluded as following.

i) It was confirmed that time-dependent diffusion coefficient obtained by the wind tunnel test decreases with increasing of time and approaches to a certain value in long time.

ii) There was no significant difference between time-dependent diffusion coefficient derived based on constant surface chloride and that based on time-dependent surface chloride.

iii) It was found that the derived two types of diffusion coefficient are all dependent of water-cement ratio of concrete but not affected by the intensity of airborne salt that the concrete is exposed.

The authors wish to express their gratitude to Brawijaya University for International Conference funding. Especially thanks to former graduate students of Nagaoka University of Technology for good working in experimental work.

\section{References}

[1] JSCE, Standard specification for concrete structures: Materials and Construction, Japan Society of Civil Engineers, Tokyo, (2002)

[2] C. Andrade and M.A. Sanjuan, Experimental procedure for the calculation of chloride diffusion coefficients in concrete from migration tests, Int. J. of Advances in Cement Research, 6(23), 127-134 (1994)

[3] C. Andrade, J.M. Diez and C. Alonso, Mathematical modeling of a concrete surface "skin effect" on diffusion in chloride contaminated media, Int. J. of Advanced Cement Based Materials, 6(2), 39-44 (1997)

[4] K.M.A. Hossain, Correlations between porosity, chloride diffusivity and electrical resistivity in volcanic pumice-based blended cement pastes, Int. J. of Advances in Cement Research, 17(1), 29-37 (2005)

[5] D. Nuralinah, K. Kamiura and T. Shimomura, A new laboratory test method for chloride ingress into concrete subjected to airborne salt, Proc. of the Twelfth Int. Summer Symposium, Chiba, Japan, 291-294 (2010)

[6] D. Nuralinah, K. Kamiura and T. Shimomura, Analysis of chloride ingress into concrete subjected to airborne salt measured by wind tunnel test, Proc. of the Japan Concrete Institute (CD-ROM), 33(1), 869-874 (2011)

[7] K. Kamiura, Development of wind tunnel for simulation of airborne salt, Master Thesis, Nagaoka University of Technology, Japan, (2009)

[8] G.S. Paul, Diffusion in solids, McGraw-Hill, New York (1963)

[9] P. Erwin and M. Leif, Diffusion of chloride in concrete, Taylor \& Francis Inc., New York (2006)

[10]R.B. Bird, E.S. Warren and N.L. Edwin, Transport phenomena, $2^{\text {nd }}$ ed, John Wiley \& Sons, Inc., New York (2002) 